\title{
INFLUENCE OF BEER LABEL DESIGN ON MAKING DECISION ABOUT CHOOSING AND BUYING PRODUCT
}

\author{
Marina Heđa, Dean Valdec (iD, Krunoslav Hajdek, Petar Miljković (iD \\ University North, Department of media design, Koprivnica, Croatia
}

\begin{abstract}
In the brewing industry there is a great competition among beer producers and the constant struggle for dominance on the market. The beer label for glass packaging is an important means of communicating with the customer and it represents a key part of the whole packaging which sells the product. This paper researches the impact of primary packaging and beer label on customer perception and purchase of products. The aim of this study was to examine customers' perception of different elements of beer label design. Survey was conducted on a hundred adult males and females aged 18 to 65 years. The sample for conducting the survey consisted of six 0.5 bottles of different types of beer placed on the shelf. Based on the results of the research, conclusions were drawn about the influence and preference of the brand, about the elements that are crucial for the decision to purchase and the efficiency of individual graphic elements of the label.
\end{abstract}

Key words: beer label, design, brand, packaging

\section{INTRODUCTION}

Beer is a product which is often consumed and belongs to a food group of products. Glass packaging is very suitable for packing beer due to its chemical and barrier properties. Dyed glass used for beer packaging is also a good light insulator that prevents the formation of harmful chemical reactions in beer caused by UV rays. Furthermore, the bottle shape itself contributes to mechanical resistance. The most efficient bottle shape is a relatively narrow bottle with a narrow long neck. According to its basic purpose, glass packaging belongs to a sales or primary packaging (Narodne-novine, 2005) which has the role of protecting and presenting the packaged product, containing information on the goods and allowing an easy use and wear of the product. Therefore, glass bottles have assumed absolute primacy in beer production. However, practice has shown that PET packaging is very practical and well accepted by consumers (Rujnić-Sokele, 2018).

Due to difficulties of printing on a glass bottle, the label is an integral part of beer packaging. Customers and label consumers have never been more demanding, more price-sensitive and more environmentally and health-conscious (Print magazine, 2018). Label represents a medium of visual communication which allows customers to get all the necessary information on the product, i.e. the information that encourages them to purchase. Since it is a product placed on the shelves in the store, the beer manufacturer can communicate with the customer exclusively through the visual display - the label. The label is a part of the packaging where the manufacturer should, by means of graphic elements, unite legally prescribed information with design elements that in a psychological way reach the customer's consciousness and encourage admiration (Solomon et al, 2006).

Consumer behaviour is influenced by a large number of factors (social, personal and psychological) which are interrelated and represent a starting point for understanding consumer behaviour (Kesić, 2006). From a marketing point of view, packaging should enable the product identification among competing products at the point of sale, contribute to the communication with the buyer, create an additional psychological value of the product, and facilitate the customer's purchase decision (Grbac \& Meler, 2007). Product identification is the main task of beer labelling which should enable the customer to clearly identify the product within the variety of other products, which usually refers to the product name that is dominant on the label (Jurečić, 2004). The label must also describe the product, i.e. it must contain the information on the type of beer, content, composition, date and place of production, method of handling, etc. Glass bottles are recycled and reused in a way that they are cleaned and prepared for reuse using specifically defined processes which are carried out in breweries and are therefore classified as returnable packaging (Stipanelov Vrandečić, 2010). 


\section{BEER LABEL DESIGN}

Label design together with the descriptive information makes the entity vital to the sale of the product, which is the ultimate goal of each beer maker. Product descriptions include all the information a customer needs in order to safely use the product. The label with its typography, colours, shape and other graphic elements has to retain its visual identity so that the customer could at first sight identify the manufacturer - the brewery (Mencer, 2011). An attractive and innovative graphic design of the label should promote the product. Due to the fact that beer is a part of a group of food products, it is allowed to be advertised. Beer producers often advertise their products regardless of its sales results. The design of the label needs to be changed after some time in accordance with its visual identity and identification of the manufacturer in order to keep the customer's attention and promote the product on the competitive market. Very often, specific beer labels are produced for events such as festivities or jubilees to promote the beer tradition.

The front label on the beer bottle is the first and most important part of the packaging that will be noticed at first by the potential buyer. The shape of the front label should be aligned with the cylindrical shape of the bottle, so in practice, the rounded forms of the front labels are often applied. It is a well-known rule that the composition of elements has a remarkable impact on the perception of the human eye and the perception of the general impression of aesthetics. The front label is placed on the body of the bottle in the optical centre, which is the imaginary line and is slightly above the geometric environment and corresponds to the ratio of the golden section. The composition of individual graphic elements on the label should show harmony in the human eye. The optical medium of the label is firstly noticed by the observer. Therefore, the name of the beer identifying the product is put in this position. Other elements are subordinated to the optical medium, and their size and position are determined by the importance of the information. When using the front label, it is important to pay attention to the amount of information since too much information in a small format may result in the lack of legibility and difficulties to find the desired data. The information on the front label should be divided into three to four groups and then adjusted to the size and placement of the text. The text on the front label of beer is most commonly written in uppercase, with the exception of the logo. Like colours, the selected fonts contribute to the brand personality (Ellis, 2018).

Illustration is often a constituent part of the label, and its role is to describe the text or to be a decorative part of the label. Illustrations on beer labels most often complement the typographic logo and describe the tradition of a particular brewery or a particular type of beer. Choosing illustrations in the form of drawings or photographs on packaging is a very complex task because the illustration speaks a lot about the product. Like the size of text, the number of colours should also be limited to several rankings in order to avoid unreadability. The beer label on the front contains textual information about the type of beer that is crucial for informing the potential buyer and its main purpose is to identify the product and aesthetically appeal to the buyer, while all other information is on the back label (Jurečić, 2004).

\section{METHODOLOGY}

The research was conducted through surveys on the persons who were not exclusively beer consumers. A sample of 100 respondents was selected without prior knowledge of their age and education, but with the same ratio of male and female respondents. The survey comprised the comparison of six different brands of beers: Pan Lager, Pan Zlatni, Carlsberg, Osječko, Karlovačko and Stella Artois. As a sample for conducting the survey, a printed real-size model was used, which represented a simulation of the shelf at a store where six types of beer were placed in glass packaging, a volume of $0.5 \mathrm{I}$. The front and back labels were visible on the glass bottles of the above beer type. Respondents were asked to reply to 10 questions after which it was possible to make a conclusion about the impact of the entire packaging on the customer, including the label and individual elements on the label. The questions were on multiple choice basis, so that the respondent could choose one of the answers which best describes his/her opinion. In addition, respondents were asked to give data on their gender, age and education. Thus, subgroups were defined within the examined sample of people providing the additional data on the subgroup preferences within the overall research.

Each of the above stated beer producers have profoundly shaped their visual identity. The colours and graphic elements on the labels have carefully been adjusted to the appearance of the bottle in order to arouse an adequate visual effect among potential customers. The goal of each label is to present the quality and the brand of the particular beer and eventually sell the product. Due to the fact that specific 
beer consumers already have certain predispositions to the above stated products as a result of their previous experience with consumption of a particular beer type, the research comprised the investigation of the visual elements which arouse a certain cognition of the product. The first step of the analysis of consumer's behaviour was to find the reason why individuals prefer one beer or the service of another beer producer (Pindyck \& Rubinfeld, 2005). The goal of the research was to establish which label design and which print design cause the most positive reactions among potential customers. Besides, it was important to determine which elements on the label attract the most attention and their impact on the decision to select and buy the particular product.

\section{RESULTS AND DISCUSSION}

The data on the age of the respondents were not previously known, nor was the targeting of a particular age group taken into account. The survey was conducted on adult persons, i.e. persons older than 18 years of age. When selecting the respondents, it was considered that the total sample covers all age groups alike, and the respondents were selected according to an intuitive visual assessment. Figure 1 shows the proportion of individual age groups of respondents according to predefined classes.

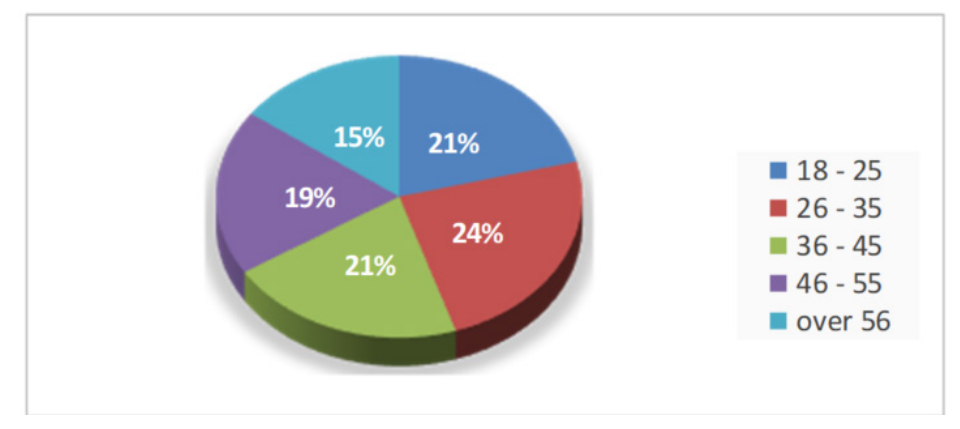

Figure 1: Ratio of respondents in the survey according to age groups

The data on the education of respondents are important for the presentation of the characteristics of the sample of the individuals surveyed. Figure 2 shows the educational profile of sample of respondents. As can be seen from the diagram below, the highest percentage comprises high-school graduates (60\%). The percentage of undergraduates is twice lower (29\%) and there are also primary school graduates (2\%).

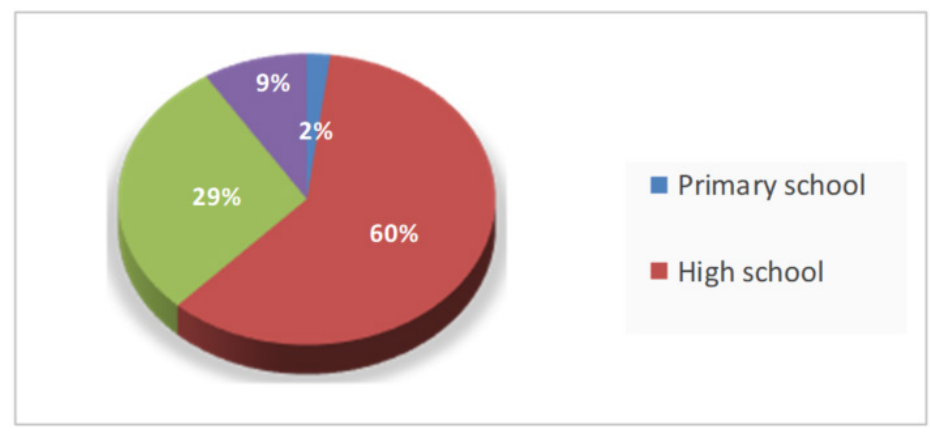

Figure 2: Ratio of respondents according to their degree of education

The question "Do you drink beer?" was replied as 'Yes' by $74 \%$ respondents. According to the gender, it was found that men consume more beer than women. A total of $82 \%$ of men claimed to consume beer while this percentage among women was 66\% (Figure 3). This issue involves drinking beer, which does not have to be frequent, but is a general guideline for buying beer, as well as being in contact with a beer label. So this survey confirms that beer is a widely consumed product. The appearance of a packaging for consumer goods needs to be taken into consideration upon designing and manufacturing, because the decision to purchase such products depends on the first few seconds of seeing the product. 


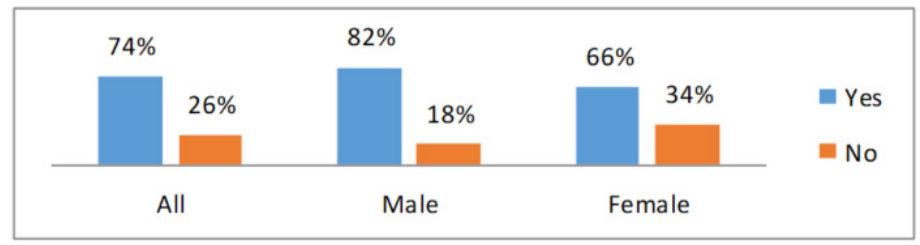

Figure 3: Ratio of respondents who consume beer

The preference to a particular brand among consumers was determined in the survey by the question "Do you always buy beer produced by the same manufacturer?". Every manufacturer's goal is to keep the customers of their products, investing considerable effort during the whole beer production process. The product itself is the most important for retaining customers, but it must be recognizable. It is the beer label that identifies a particular product and makes it recognizable. Due to the preference of the product on the store shelf, a particular consumer group seeks the label of its favourite beer, not paying particular attention to the label of other beer producers. However, a group of people experimenting with the consumption of different beers from different manufacturers is the main target group which may be affected by the appearance of the product and its advertising. People who do not always buy the same beer are prone to buying beer with a new label or even a new type of beer. The complexity of this area of research is the fact that it comprises two opposite concepts of the brand. There are people who are inclined to buy only their favourite brand, and people to whom it is not important who the manufacturer is. The research results have shown that most people (58\%) buy beer by the same manufacturer. The tendency to buy the same beer is specifically present among men (74\%), while women often buy various kinds of beer $(42 \%)$.

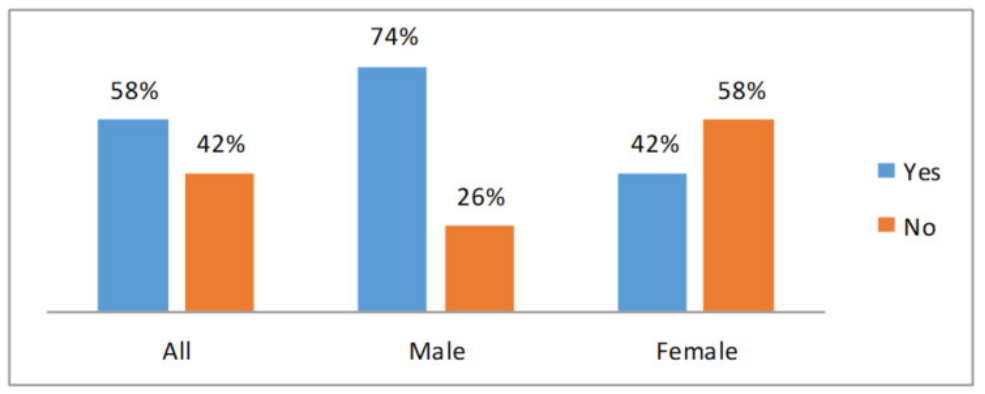

Figure 4: Respondents' ratio in tendency to buy a certain beer brand

When choosing which beer to buy, buyers have different criteria crucial upon selecting a particular beer. The taste of beer plays the most important role to a particular group of consumers when buying beer, while the appearance and the function of packaging are regarded as the less important beer selection criterion. Price represents the relationship between supply and demand of goods conditioned by the product brand. Price is a factor that significantly affects the selection and purchase of beer. Buyers are often willing to buy a cheaper product, ignoring the taste and quality of beer. The appearance and functionality of packaging also significantly influence the decision to buy beer. The design of packaging is especially important to buyers who do not consume beer, but only buy it for other person's consumption. Innovations regarding beer as a product and its packaging influence the buying decision because buyers like to experiment with products they often use, so they are often ready to buy a beer with a new taste or in a new and different packaging. The results of the research (Figure 5) show that beer taste is the most important criterion for beer selection and buying (31\%), but price (28\%) and packaging (27\%) also play an important role, while product innovation is the least important criterion. The taste of beer is especially important for men while women pay more attention to the price of the product. 


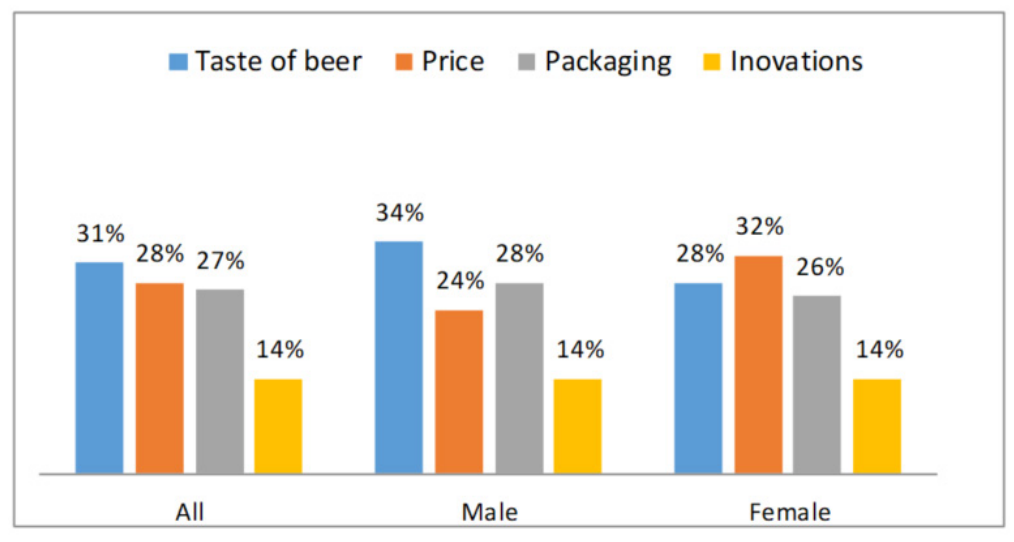

Figure 5: Impact of taste, price, packaging and innovativeness on beer selection

The reason why a customer buys a particular product, not the one produced by competition, represents a very important information for every manufacturer. It is in the interest of any manufacturer to know what is important in view of their beer packaging and label and what exactly attracts the buyer and makes him/her buy the beer if the content of the packaging is left out. Brand is a quality that buyers notice and is based on the experience they associate with the product. The goal of each manufacturer is to create a brand because the recognition of the product is sometimes a sufficient reason to purchase. Brand is a marketing phenomenon that sometimes creates the whole corporate culture based on a product or name. Therefore, a buyer who buys a particular brand feels as a part of the community which consumes that same beer. There is a very strong link between the manufacturer and the customer and it requires a lot of time and experience to create it. The design of the packaging and the label also make a very important effect on the purchase decision. The customer wants to experience pleasure, as it is the case with all other staff he/she owns. An attractive appearance plays an important role upon purchase decision due to the fact that individuals make visual perceptions of the product. The functionality of the packaging itself can also have a major impact on the purchase, whereas to some people neither the brand nor the appearance is important, but the way in which the product is opened and consumed.

The research results (Figure 6) have shown that the brand (43\%) is more important than functionality $(24 \%)$ and packaging design (33\%), especially to men (46\%), whereas women consider packaging design equally important (brand - 40\%; packaging design - 40\%).

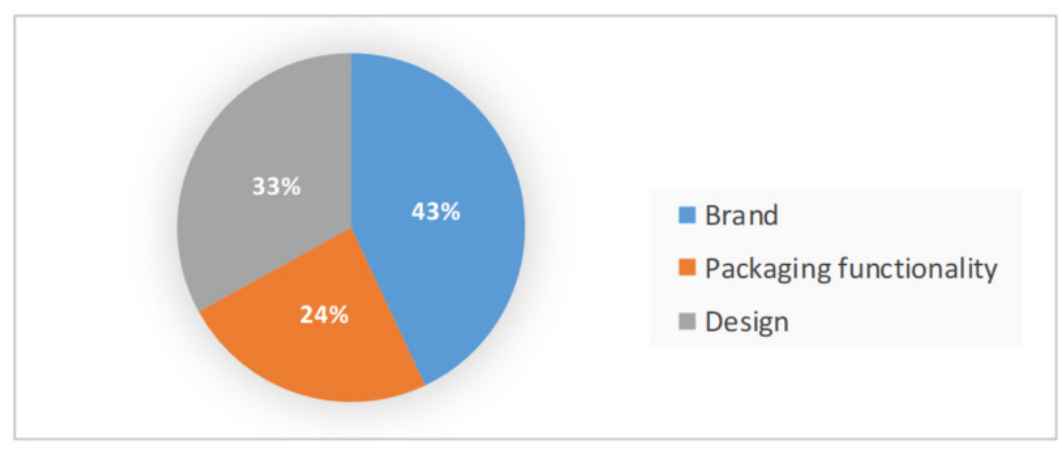

Figure 6: Impact of brand, functionality and design of packaging on beer selection

The question in the survey 'To what extent can the label design affect your purchase decision?' should investigate the customer's sensitivity to visual information on the label. The informations are created and designed to represent the product. Their composition, colours and position on the packaging should cause a positive visual reaction of the buyer. The impact of the layout of the label is not questionable. However, it is important to determine to what extent it affects a purchase decision. The awareness on the impact is an important factor upon creation of new elements on the label. The manufacturer is thus able to know the ratio of the people who will be interested in the new label or who will recognize the importance of a good design of the existing label and the existence of the label in general. 
The research results (Figure 7) have confirmed the effect of the label design on the purchase decision. Most respondents are aware of the effect of the label design (it affects sometimes - 39\%; it affects always - 45\%). However, the label design makes an impact on the choice of beer only to $9 \%$ of respondents. The effect of the label design is higher among female respondents (54\%) than among male respondents (46\%).

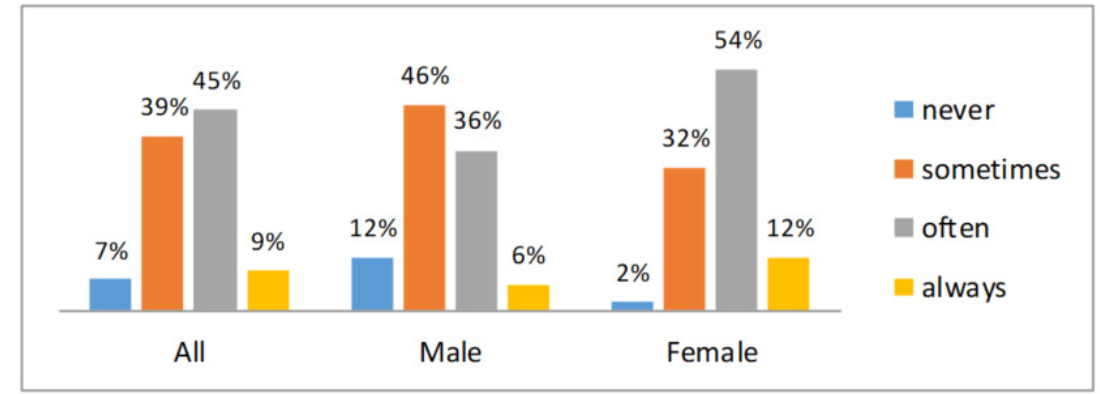

Figure 7: Effect of label design on beer purchase decision

The questions presented below refer to the concrete beer samples: Pan Lager, Pan Zlatni, Carlsberg, Osječko, Karlovačko and Stella Artois. The photographs of beer samples on the shelf were presented to respondents during the survey (Figure 8).

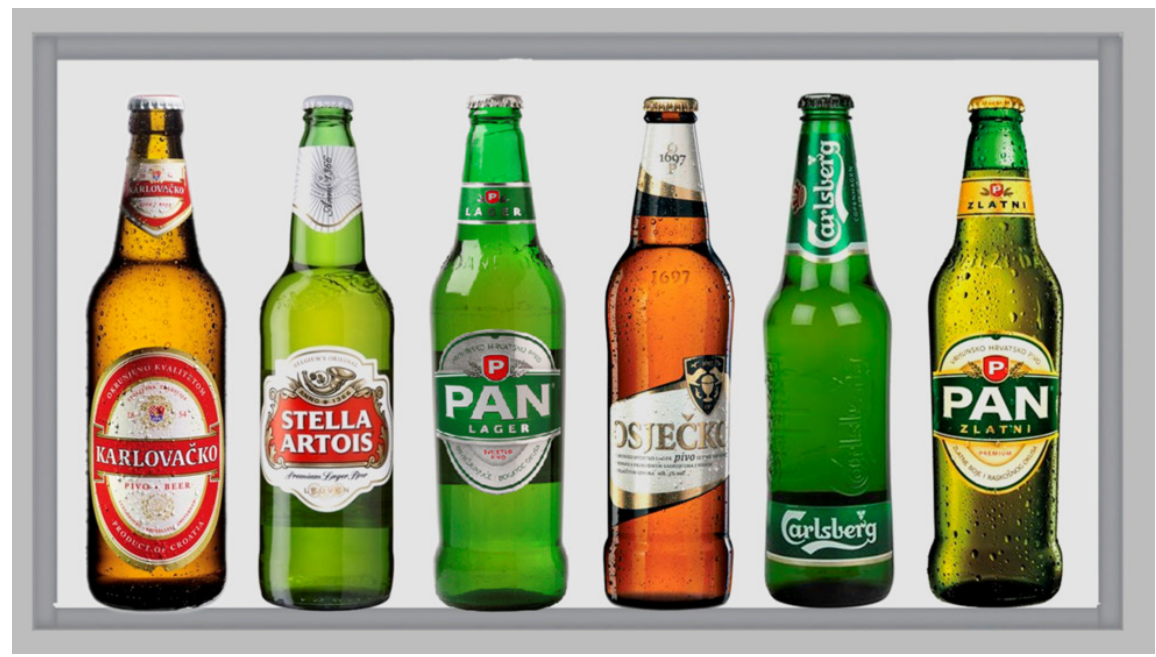

Figure 8: Beer samples compared in the survey

The question "Which of the labels most attracts your attention?" should determine the performance of a particular label to attract customer attention at a certain time. In direct sales of the product where the customer comes into direct contact with the product, it is extremely important for the customer to notice the product as soon as possible. In order to gain attention, the first few seconds are crucial when several different products of the same type are placed in front of the customer. The goal of every manufacturer is that their product is the first to be seen. The appearance of beer labelling plays a leading role in attracting attention, because the packaging of all beers packed in glass bottles is very similar. The bottle is designed so that the buyer notices its content, i.e. beer but not the kind of beer and the manufacturer. The label identifies the brand, and its appearance is a key indicator of beer type.

The results of the research (Figure 9) show that beer labels Stella Artois, Osječko, Pan Zlatni and Karlovačko are almost equally observed, while beer labels Carlsberg and Pan Lager draw less attention compared to the above stated labels. The labels that are most noticeable in the survey attract attention by the combination of easily visible colours such as red and shiny surfaces in gold, as well as the contrast between them and are placed in the centre of the packaging. The results show that the Carlsberg beer is the lowest positioned, so it can be concluded that the reason for this is the expectation of the observer that the label is placed in the middle of the bottle at the most visible location, which is not the case with this packaging sample. 


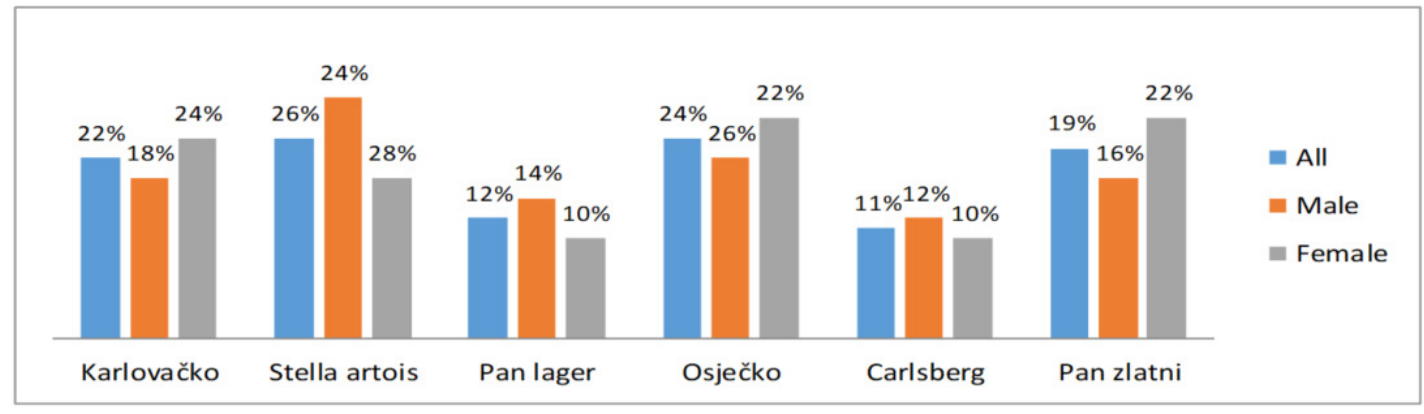

Figure 9: Ability of specific labels to attract customer's attention

The combination of colours on the beer label enables the perception of design elements. The selection of colours on the label describes the character of the product, i.e. the type of beer. Colour psychology has a great influence on marketing and customers are often unaware of these facts. It has been shown that colours arouse different moods and associations in humans, and that the human brain subconsciously associates certain experiences with colours. It has been determined that beer labels are dominated by white, green, red, gold, silver and black. Based on the knowledge of colour psychology, it could be concluded that these colours are intended to achieve the recognition of natural and high quality products. However, label designers use different shades to show the colour that is most similar to the colour of beer, as there are less and more bitter beers of various volumes of alcohol and different basic ingredients. The question "Which colour label best suits your expectations of beer?" should determine the success of the manufacturers in this field. Only respondents who claimed to consume beer were participated in this part of the survey in order to get better results, since people who do not consume beer have no expectations of the taste of the product. The results of the research (Figure 10) show that the combination of colours on the beer labels of Karlovačko, Osječko and Pan Zlatni best present the beer taste.

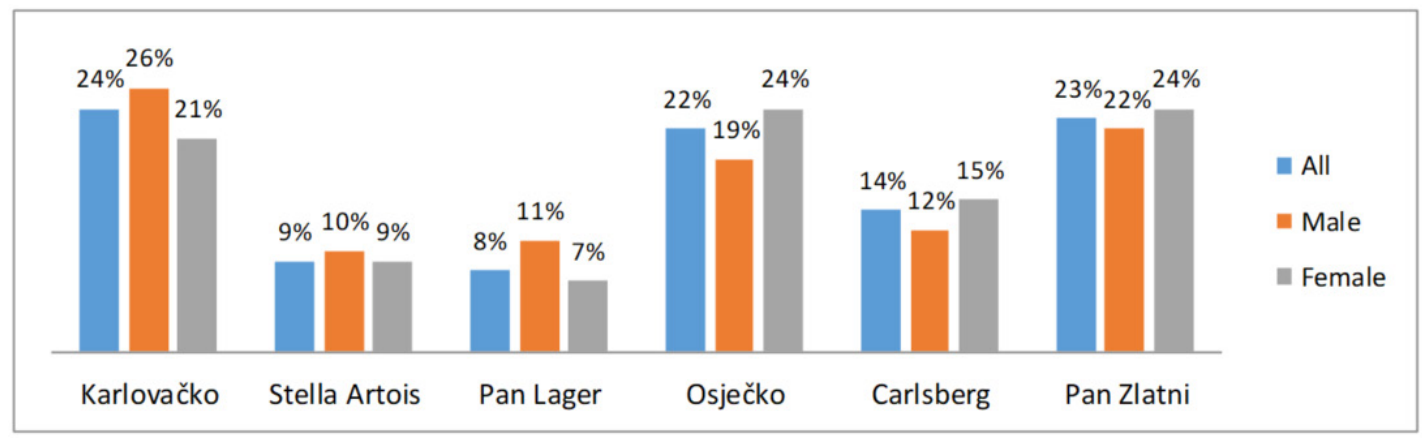

Figure 10: Perception of beer taste in view of colour combinations on the label

The elements on almost every beer label are the name of beer, information on the type of beer, an illustration that more closely describes the character of the beer or the producer and the background that contains the elements mentioned. All of the above elements are very important for the success of product presentation and successful sales. The name of the beer identifies the brand, the information on its content is necessary for the purchase decision because it tells what kind of product is contained in the packaging, while the illustration keeps the attention. The background or background texture used to form the background serves to attract the attention of the customer. The question "Which of the graphic elements have you first noticed?" should determine how much the particular elements of the label format and their size are associated with making beer selection decisions.

The results of the research (Figure 11) show that the name of the beer is first perceived. The name of the beer is located at the most visible place of the label in all beer samples and is considerably higher with respect to other typographic contents. It is highlighted by contrasting paint with the backing. The second place takes up the background colour or texture that dominates the label (31\%). 


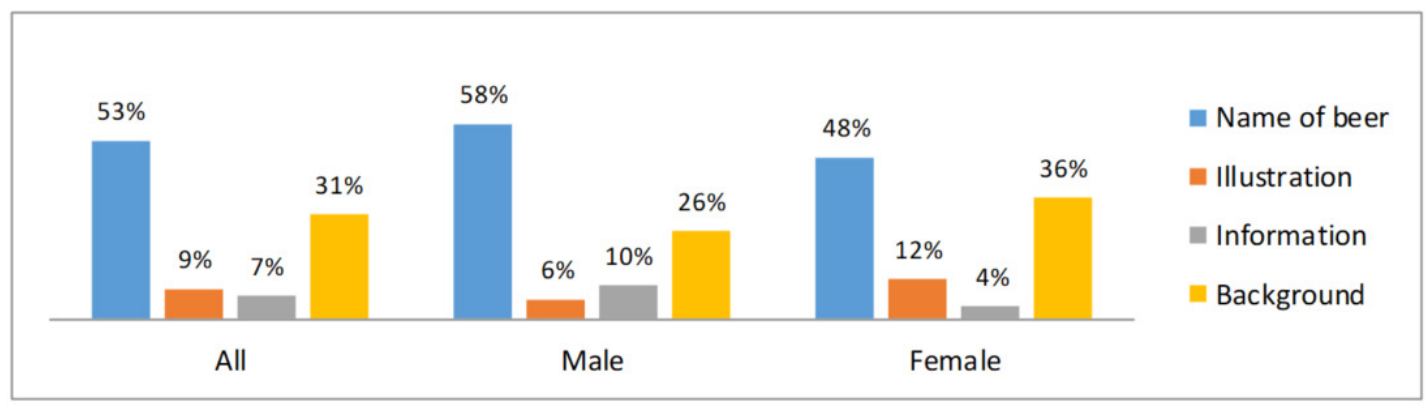

Figure 11: Effect of specific graphic elements on the label on beer selection

Production of a label consists of a series of related production processes. In order to create a graphic product of high quality which should present and promote the sales of the specific beer the co-operation of various market research experts, graphic designers and print technology professionals is required. When making a label, the goal is to get the best quality label at a lower price. However, although a label is relatively inexpensive, the editions are so large that any shift in the quality of the material used results in increased costs of a client. Despite the fact that beer is almost consumed by all the people and that sales are not questionable, significant resources are invested in the quality of the print and appearance of the label itself. The reason is a psychological experience with customers when they see something of a good quality.

Metalized paper used in the production of labels is applied because it has been proved that customers prefer shiny prints since the labels on plain paper do not point to high quality. Therefore, almost all manufacturers have introduced metallized papers into the process of producing their labels. Due to the effort invested in the quality of the label, the goal is that potential customers who do not necessarily have knowledge on printing and its capabilities recognize this quality. The survey investigated the success of comparable beer brands in recognizing and understanding the quality of label prints by consumers.

The quality of labels as graphic products in terms of print quality (Figure 12) was perceived by the respondents in all the samples with slight deviations. This information confirms that the beer label is a quality graphic product. High quality beer label printing is required for reasons of competitiveness with other manufacturers, as a proof of the quality of the brand and the durability of the label regarding mechanical influences when storing and handling.

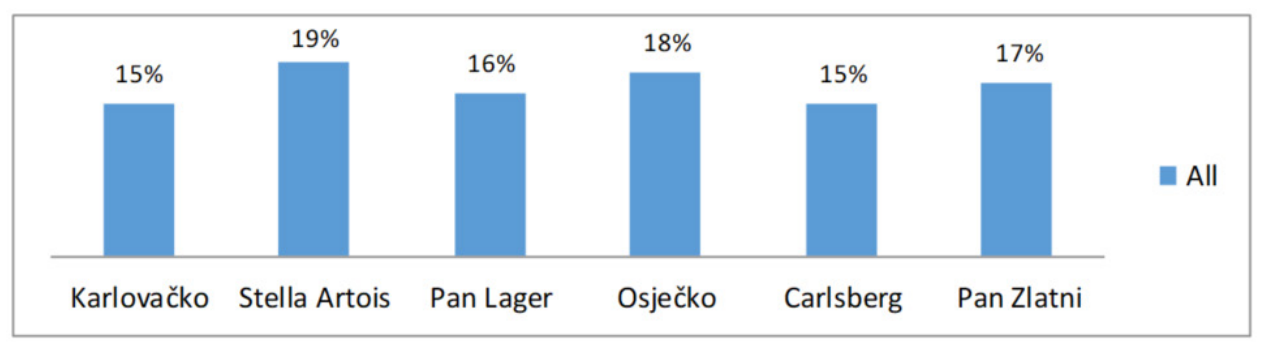

Figure 12: Perception of label quality in view of print quality

\section{CONCLUSIONS}

Based on the results of the research and the analysis of the results, conclusions are drawn on the influence and preference of the brand, the influence of the elements that are crucial to the decision to purchase and the productivity of some graphic elements on the label format. If the purchasing power with regard to the degree of education is not considered, it should be based on the fact that beer is a "popular" drink which everyone buys without being conditioned by a great purchasing power. Therefore, the appearance of the label must attract as many different target groups as possible.

Of all the participants who participated in the survey, 58\% claimed they always bought beer from the same producer. These data indicate a rather great tendency to the purchase a particular brand. Men are more inclined to buy their favourite beer since research results show that as many as $74 \%$ of men always buy beer from the same producer. In female population this figure is considerably lower - $42 \%$. The reason may lie in the fact that women consume less beer and show a tendency to seek new flavours. 
In view of beer packaging, the brand is together with its appearance the most important factor affecting the buying decision. Men (46\%), in higher proportion to women (40\%), stress the brand as the most important factor. The name of the beer on the label is besides its colour the main representative of the brand and the beer producer. As many as 53\% of respondents said the name of beer was the part of the label they first noticed. This information points to the significance of the brand as the most important factor in the entire brewing industry. The above stated data point to the conclusion that beer is a product which is primarily sold on the basis of a preference for a particular brand. Manufacturers recognize the importance of highlighting their brands, so beer labels are made in line with total visual identity for faster recognition.

The label has a significant impact on the sale of products, which is confirmed by the large share of respondents (45\%) who responded in the survey that they are aware that the appearance of the label often affects beer selection. Apart from the content information on the product, the label significantly influences the sale by its design and aesthetic attractiveness. Women are especially prone to a visual impression. An attractive packaging is the most important reason for buying beer among as much as $42 \%$ of women who put it in the first place ahead of the brand's importance (40\%) or packaging functionality (18\%). Print quality can also affect sales of products because people want quality products. People think that quality prints are associated with a quality product and are therefore willing to buy a product that is in a more attractive and high quality packaging.

A good layout of the elements on the surface of the label, their size and contrast result in fast perception of the entire label. The research has shown that larger labels with stronger colour contrast and larger typographic elements are instantly noticed. The contrast between typography and background is conditioned by good readability, which results in the perception speed. Manufacturers recognize the importance of highlighting their name, and therefore this element is placed in the most visible place of the label. The name of the beer is so important that it stands out in several places on the entire packaging, for example, some labels on the bottleneck contain only a logo, and it is also highlighted on the back labels if the packaging contains them.

In comparison to the information recorded by typography, more important are regarded the information on the type of beer, origin and volume of alcohol, which can in some cases be found on the front label.

The illustrations are placed close to the logo and are primarily used to keep the viewer's attention on the label. They are usually painted in red, which is known as the colour that attracts one's attention. The illustrations show the character of beer or some drawings related to the brewery tradition. The background lines, textures, and coloured surfaces round off the look of the label and emphasize the information that the label contains. They are designed in accordance with the shape of the label, and their colour is aligned with other elements that are the carriers of information. Beer labels do not usually contain much colour, but are simple and easy to read.

Beer labels are high quality graphic products for the purpose of presenting and selling beers, as well as most of the printed packaging products. The quality of these products is conditioned by customer requirements whose goals are to get the most quality product at a lower price. Since customer satisfaction is the ultimate goal and the main bearer of the long-standing success of every brewery, advertising materials such as the label requires a lot of time and large investments into material resources to help customers recognize their quality and dedication.

\section{REFERENCES}

[1] Ellis, M.: "How to design a beer label: the ultimate guide for craft brewers", 99designs, URL: https://99designs.com/blog/packaging-label/beer-label-design/ (last request: 2018-07-23)

[2] Grbac, B., Meler, M.: "Realizacija poslovne ideje - Od ideje do proizvoda/usluga", (ZT Zagraf, Zagreb, 2007).

[3] Jurečić, D.: "Evaluacija elemenata vizualne informacije na grafičkoj opremi ambalaže", Magistarski rad, Sveučilište u Zagrebu, 2004.

[4] Kesić, T.: "Ponašanje potrošača, II. izmijenjeno I dopunjeno izdanje", (Opinio d.o.o., Zagreb, 2006).

[5] Mencer, I.: "Politika marketing miksa", (Rijeka, 2011).

[6] Narodne-novine, Ministarstvo zaštite okoliša, prostornog uređenja i graditeljstva: "Pravilnik o ambalaži i ambalažnom otpadu", Narodne novine broj 97/05 i 115/05, URL https://narodne-novine.nn.hr/clanci/sluzbeni/2005_08_97_1894.html (last request: 2018-08-18)

[7] Pindyck, S.R., Rubinfeld, L.D.: "Mikroekonomija", 5, (Mate, Zagreb, 2005). 
[8] Print magazin, Etikete i etiketiranje, Print-magazin,

URL: https://www.print-magazin.eu/etikete-i-etiketiranje/ (last request: 2018-09-19)

[9] Rujnić-Sokele, M.: "Plastična ambalaža - najbolji izbor za okoliš", Polimeri, 32(2), 92-94, 2018.

[10] Solomon, M. R., Bamossy, G., Askegaard, S.: "Consumer Behaviour: A European Perspective", $3^{\text {rd }}$ ed, (Prentice Hall, London, 2006).

[11] Stipanelov - Vrandečić, N.: "Ambalaža", (Kemijsko-tehnološki fakultet, Split, 2010).

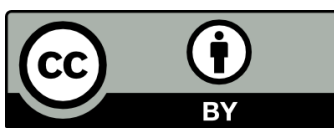

(C) 2018 Authors. Published by the University of Novi Sad, Faculty of Technical Sciences, Department of Graphic Engineering and Design. This article is an open access article distributed under the terms and conditions of the Creative Commons Attribution license 3.0 Serbia

(http://creativecommons.org/licenses/by/3.0/rs/). 